\title{
Role of epithelial hyperplasia in regression following photorefractive keratectomy
}

Cooperative Research Centre for Eye Research and Technology, and Cornea and Contact Lens Research Unit, School of Optometry, University of New South Wales, Sydney, Australia C A Gauthier B A Holden

Department of Ophthalmology, University Hospital, Uppsala, Sweden D Epstein

St Erik's Eye Hospital, Karolinska Institutet, Stockholm, Sweden B Tengroth P Fagerholm H Hamberg-Nyström

Correspondence to: Charline Gauthier, $\mathrm{PhD}$, Cooperative Research Centre for Eye Research and Technology, University of New South Wales, Sydney, NSW 2052, Australia.

Accepted for publication 11 March 1996

Charline A Gauthier, Brien A Holden, Daniel Epstein, Björn Tengroth, Per Fagerholm, Helene Hamberg-Nyström

\begin{abstract}
Aim-To determine the relation between epithelial hyperplasia and regression of effect after photorefractive keratectomy (PRK).

Methods-Seventy unilaterally treated patients with PRK were examined. All eyes had been treated with the Summit excimer laser 27 (SD 7) months previously with zone diameters of 4.1 to $5.0 \mathrm{~mm}$. The untreated fellow eyes served as controls. Epithelial thickness was measured centrally with a thin slit optical pachometer and manifest subjective refraction was performed.
\end{abstract}

Results-The epithelium was $21 \%$ thicker in the treated eye $(p<0.0001)$. The relation between refractive regression and epithelial hyperplasia was significant $(r=0.41$; p<0.001).

Conclusions-Epithelial hyperplasia after PRK correlated with the myopic shift (including hyperopia reduction) after treatment with the Summit laser. A model is proposed suggesting that both subepithelial and epithelial layers contribute to regression in the Summit treated eyes with $18 \mu \mathrm{m}$ of epithelial hyperplasia contributing each dioptre of regression.

(Br F Ophthalmol 1996;80:545-548)

Despite the growing popularity of photorefractive keratectomy (PRK) and the relatively high patient satisfaction with the results, ${ }^{1}$ the problems of individual predictability and long term stability of refraction remain. The aetiology of myopic regression is still unclear. $^{23}$ It has been widely suggested that there is a relation between regression and epithelial hyperplasia and/or stromal remodelling. ${ }^{2}$ 4-8 Epithelial hyperplasia has been reported histologically ${ }^{9-24}$ and clinically. ${ }^{25}$ However, the relation between epithelial hyperplasia and refractive changes has not been investigated.

Epstein $e t a l^{26}$ have questioned the stromal remodelling hypothesis with their report of the presence of the original pattern of laser ablation rings below the epithelium as long as 2 years after surgery. We have yet to understand the ways in which different components of the corneal wound healing process contribute to the postoperative refractive outcome.

The aim of this study was to determine if there is a relation between epithelial hyperplasia and refractive regression (myopic shift) after PRK.

\section{Materials and methods \\ SUBJECTS}

We examined subjects who had previously had PRK performed on one eye for correction of myopia (Table 1). Out of approximately 800 patients treated at our clinic with the Excimed UV200LA excimer laser (Summit Technology, Waltham, MA, USA), 216 were unilateral at the time the study was conducted. Study subjects were asked to participate by letter or in person in advance or when they presented to the clinic for their regularly scheduled follow up, and 70 were able to participate. The reasons why the participating subjects remained unilaterally treated are given in Table 2. All eyes were free of any obvious ocular disease. Informed consent was obtained from all subjects.

The unoperated eye was used as the control in all cases. Subjects were asked to remove their contact lens from the untreated eye at least 1 night before the study visit. Five subjects presented to the clinic wearing soft lenses in their control eye and the lenses were removed immediately. Although contact lens induced hypoxia may cause stromal swelling, O'Leary $e t a l^{7}$ have shown that the corneal epithelium does not swell even after 6 hours of anoxia. Therefore contact lens induced oedema would not be expected to have affected the epithelial thickness and these subjects were included in the study.

\section{SURGICAL PROCEDURES}

All patients had PRK performed for myopia by one of four surgeons (BT, DE, PF, HHN). All surgeries were performed in Stockholm, Sweden. Surgical factors are summarised in Table 1.

The surgical procedure was preceded by topical anaesthesia with amethocaine (tetracaine) $0.5 \%$, and marking of the treatment zone. With the patient fixating an internal fixation target within the laser, a $5.0 \mathrm{~mm}$ radial keratotomy marker with cross hairs was centred on the entrance pupil and pressed on the cornea to delineate the treatment zone. Removal of the central corneal epithelium was performed manually with a Beaver blade (Becton Dickinson, AcuteCare, Franklin Lakes, NJ, USA). With the patient again fixating the same target, PRK was performed with the Summit argon fluoride laser with spectral emission at $193 \mathrm{~nm}$ and pulse frequency fixed at $10 \mathrm{~Hz}$. The pulse energy resulted in a radiant exposure of $180 \mathrm{~mJ} / \mathrm{cm}^{2}$. The number of pulses was computed by a proprietary algorithm. All subjects had less than $1 \mathrm{D}$ of astigmatism and 
Table 1 Subject details and laser variables

\begin{tabular}{ll}
\hline Sample size & 70 \\
Males:females (\%) & $56: 44$ \\
Right eyes treated & 51 \\
Age at time of study (years): & $34(9)$ \\
$\quad$ Mean (SD) & 21 \\
Minimum & 55 \\
Maximum & \\
Follow up time (months): & $27(7)$ \\
Mean (SD) & 13 \\
Minimum & 37 \\
Maximum & \\
Attempted correction (D): & $-4.1(1.5)$ \\
Mean (SD) & -1.8 \\
Minimum & -8.0 \\
Maximum & 10 \\
Pulse frequency (Hz) & 180 \\
Pulse energy (mJ/cm $\left.{ }^{2}\right)$ & $4.6(0.2)$ \\
Ablation zone diameter (mm): & 4.1 \\
$\quad$ Mean (SD) & 5.0 \\
$\quad$ Minimum & \\
Maximum & $36(13)$ \\
Ablation depth ( $\mu$ m): & 15 \\
$\quad$ Mean (SD) & 74 \\
$\quad$ Minimum & \\
Maximum & \\
\hline
\end{tabular}

were treated with spherical ablations. Emmetropia was the desired outcome in all eyes. Patients received an ablation with a diameter of $4.1(n=2), 4.3(n=6), 4.5(n=47)$, or $5.0 \mathrm{~mm}$ $(n=15)$.

Postoperative treatment consisted of cinchocaine-bibrocathol ointment (a combination of a topical anaesthetic and an antiseptic component in a paraffin/Vaseline base) for 1 day and patching overnight. Topical steroid (dexamethasone $1 \mathrm{mg} / \mathrm{ml}$ ) therapy was started on the first postoperative day. Patients were either treated for 3 months (five times daily for 1 month, three times daily for 1 month, and once daily for 1 month) or for 5 weeks (five times daily for the first week, with a subsequent reduction of dose by one drop per week). Two subjects were not prescribed corticosteroid treatment immediately after surgery. Topical dexamethasone was reinstituted in $26 \%$ of Summit subjects for regression to a myopia of at least $0.50 \mathrm{D}$. One subject was using topical dexamethasone once daily at the time of the study.

\section{STUDY PROCEDURES}

\section{Epithelial thickness}

Epithelial thickness measurements were performed by one unmasked observer (CAG). The Payor-Holden micropachometer, a HaagStreit optical pachometer adapted to a Rodenstock Model 2000 slit-lamp, was used to measure epithelial thickness. ${ }^{28}{ }^{29}$ The instrument allows epithelial thickness measurements to be made by utilising a higher illumination level

Table 2 Reasons why subjects remained unilaterally treated

\begin{tabular}{lc}
\hline Reason & $\begin{array}{l}\text { Number (\%) } \\
\text { of subjects }\end{array}$ \\
\hline Residual refraction error & $29(41)$ \\
Monovision by choice & $22(31)$ \\
Haloes around lights at night & $8(11)$ \\
Surgery of fellow eye booked & $2(3)$ \\
Waiting for sufficient time between eyes & 0 \\
Not needed in other eye & $5(7)$ \\
Financial strain & $4(6)$ \\
\hline
\end{tabular}

(600 000 lux), higher magnification (32x), thinner slit width $(12 \mu \mathrm{m})$, and wider angle between observation and illumination systems $\left(73^{\circ}\right)$ than those used in conventional optical pachometry. It has an accuracy of 4-7 $\mu \mathrm{m}$ depending on the experience of the user. The pachometer was fitted with a precision potentiometer to monitor electronically the position of the rotatable pachometer plate to an accuracy of 3 minutes of arc. The voltage output generated by the potentiometer is input directly into a personal computer which is programmed to convert voltage readings to thickness values and store readings for each subject. This data storage system guards against examiner bias by automatically storing the thickness values in the computer without the examiner being aware of the results during measurement. The corneal measurement location is maintained vertically and horizontally by two small alignment light emitting diodes (LEDs). These lights also ensure normality of the incident light with the corneal surface. The pachometer system was calibrated using a series of hard contact lenses of known thickness.

Epithelial thickness was measured at a central corneal position located by having the subject fixate the light used for vertical alignment. Ten measurements of epithelial thickness were made for each of the averaged recorded values. The average standard deviation of the 10 measurements was $3 \mu \mathrm{m}$. The difference between the two eyes was taken as the PRK treated eye value minus the control eye value.

\section{Manifest subjective refraction}

Manifest refractive error was determined using standard subjective techniques without cycloplegia. Refraction was performed by a trained ophthalmic technician at the 1 month visit and by the operating surgeons at the 3,6 , $9,12,18,24,30$, and 36 month visits. One independent observer (CAG) performed the refraction during the study visit at which epithelial thickness was measured.

For the purposes of this paper, the total amount of refractive regression was calculated as the change in refraction from the first postoperative visit ( 1 month) until the study visit. Therefore, total regression includes hyperopia reduction as well as any additional regression from emmetropia to a myopic state. Refractive error is expressed as the spherical equivalent in all analyses.

\section{STATISTICAL ANALYSIS}

Pearson's product moment regression analysis was used to determine relations between two sets of data. A paired Student's $t$ test was used to test for differences between eyes in the same subject. A proportions test was used to detect differences between two percentages. A one way analysis of variance (ANOVA) was used to test for significant differences in epithelial hyperplasia among regression groups. The Student Newman Keuls test was used to determine which of these groups were different. 
A $95 \%$ confidence level was chosen to denote statistical significance and all statistical tests were two tailed.

\section{Results}

EPITHELIAL THICKNESS

The mean epithelial thickness in the PRK eye was 69 (SD 8) $\mu \mathrm{m}$ (range 52-95 $\mu \mathrm{m}$ ) and in the control eye was 57 (7) $\mu \mathrm{m}$ (range 38-75 $\mu \mathrm{m}$ ). The epithelium in the PRK eye was significantly thicker by $12(10) \mu \mathrm{m}(21 \%)$ compared with the control eye $(p<0.0001 ; 95 \%$ confidence interval 9.35 to $14.3 \mu \mathrm{m}$ ).

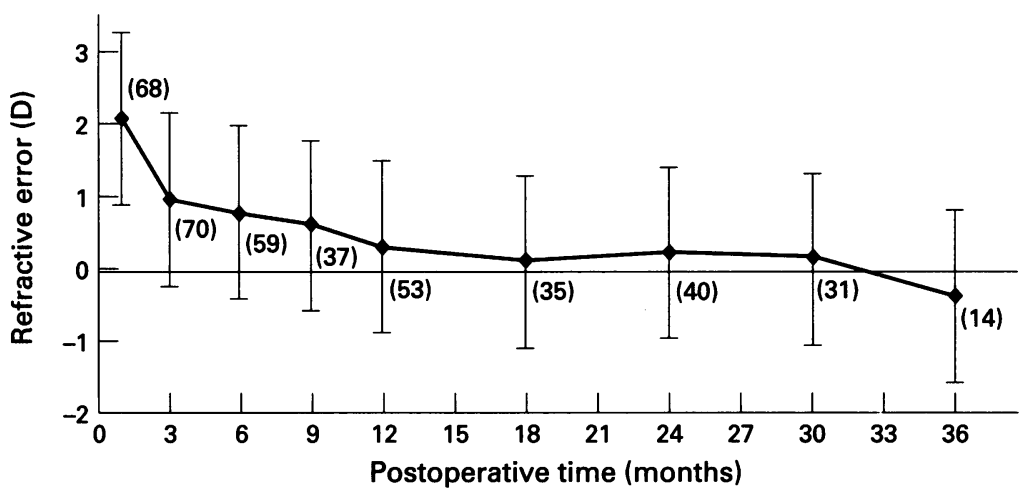

Figure 1 Postoperative refractive error (D) over time (months). Figures in brackets represent the sample size at each time point. Error bars represent standard deviations.

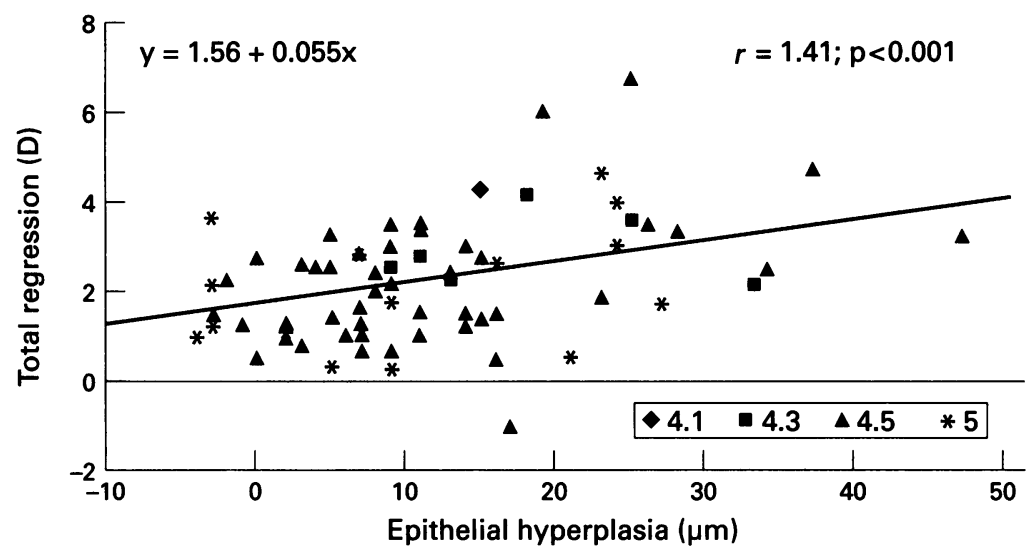

Figure 2 Total regression (D) versus epithelial hyperplasia $(\mu \mathrm{m})$. The thick line represents the regression line.

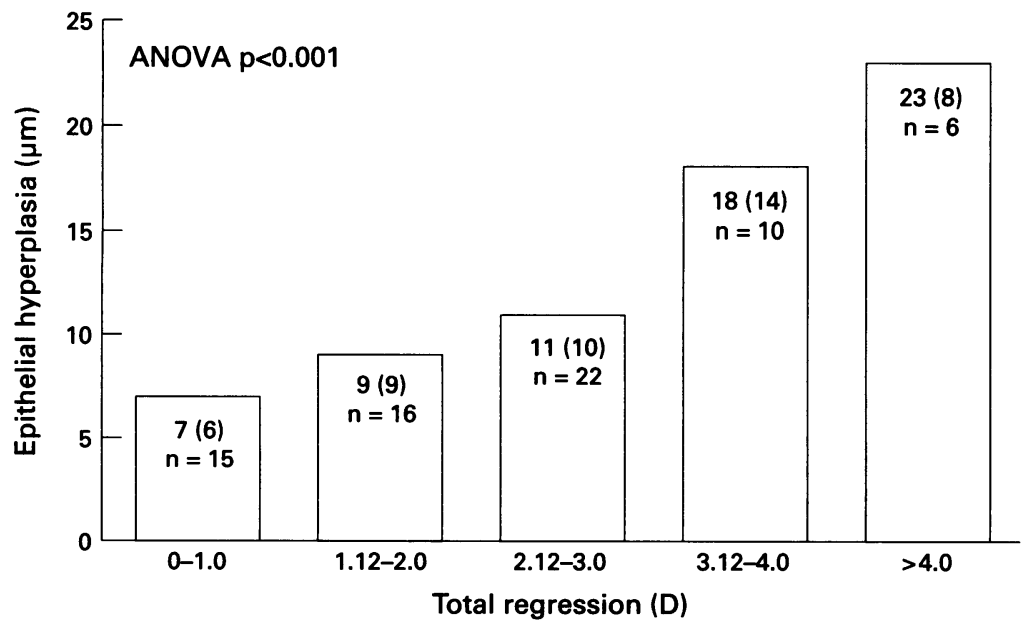

Figure 3 Mean amount of epithelial hyperplasia $(\mu \mathrm{m})$ versus total regression divided into groups of $1 \mathrm{D}$ steps for the Summit eyes. The means (SD) are shown in the bars.
MANIFEST SUBJECTIVE REFRACTION

Figure 1 shows the mean refractive results over 36 months.

EPITHELIAL HYPERPLASIA VERSUS REGRESSION The relation between epithelial hyperplasia and total regression was highly statistically significant $(r=0.41 ; p<0.001$, Fig 2$)$. Calculation of the relation between epithelial hyperplasia and regression based on the equation derived in Figure 2 predicts that without hyperplasia there is a regression of $1.56 \mathrm{D}$, and for each additional $10 \mu \mathrm{m}$ of hyperplasia there is $0.55 \mathrm{D}$ of regression ( $18 \mu \mathrm{m}$ for each dioptre of regression).

Figure 3 shows the mean epithelial hyperplasia grouped by the amount of total regression (ANOVA, $p<0.001$ ). There was a statistically significant difference in epithelial hyperplasia (a) between groups with total regression from $0.00 \mathrm{D}$ to $3.00 \mathrm{D}$ and the group with greater than $4.00 \mathrm{D}$ of total regression, and (b) between groups with total regression from $0.00 \mathrm{D}$ to $2.00 \mathrm{D}$ and the group with regression of $3.12 \mathrm{D}$ to $4.00 \mathrm{D}$.

\section{Discussion}

The aim of this study was to determine the contribution of epithelial hyperplasia to refractive regression after PRK. Owing to the cross sectional nature of the study design, subjects who where unilaterally treated were chosen so that the untreated eye could be used as a control. The authors acknowledge that this group of patients may not be representative of PRK patients in general as the study group had chosen not to have their fellow eye treated.

It has been postulated that regression is caused by epithelial hyperplasia and/or development of new stromal collagen. ${ }^{236}$ Some authors have suggested that reduction of the initial overcorrection is due to epithelial hyperplasia and that stromal regeneration is the major source of the remaining regression. ${ }^{5}{ }^{30}$ It has also been proposed that regression is related to the formation in the laser created 'bowl' of a subepithelial layer containing hyaluronic acid and other glycosaminoglycans which can alter corneal hydration and consequently affect corneal curvature. ${ }^{12}{ }^{31}$ Wilson et $a l^{2}$ hypothesised that the healing of the corneal epithelium during the early postoperative period results in an artificial and temporary hyperflattening of the corneal contour which would occur if the epithelium was thicker in the periphery than in the centre of the ablation, giving apparent initial overcorrection. They also suggested that a more pronounced stromal swelling at the wound edge could account for the apparent but temporary overcorrection.

The results of this study show that refractive regression is related to the central epithelial hyperplasia occurring postoperatively in eyes treated with small $(5 \mathrm{~mm}$ or less) ablation zones. This regression consists largely of a reduction in hyperopia occurring in the early postoperative months (Fig 1). Since all of the subjects in this group were examined 12 months after the operation, it is not possible to confirm the time course of epithelial hyperplasia. However, based on the refractive data collected 
and the correlation of the refractive regression with the measured epithelial hyperplasia, it seems reasonable to hypothesise that most of the hyperplasia develops in the early postoperative months since this is when the greatest rate of reduction in hyperopia occurs. In quantitative histological studies of epithelial thickness after PRK in monkeys, Beuerman et $\mathrm{al}^{13}$ found that the epithelium increased in thickness over the first year reaching maximum thickness at 12 months after operation with inconsistent changes thereafter. Others have found histological evidence of hyperplasia within the first month after ablation. ${ }^{14-16}$ Reduction of the initial overcorrection because of epithelial hyperplasia has also been proposed by different authors. ${ }^{530}$

It has been proposed in this study that in the absence of epithelial hyperplasia there was $1.56 \mathrm{D}$ of regression, and for each $18 \mu \mathrm{m}$ increase in epithelial thickness there was a $1 \mathrm{D}$ increase in regression. This model of regression suggests that there is a non-epithelial component accounting for approximately 1.50 $\mathrm{D}$ of regression and the remainder of the regression is due to epithelial hyperplasia. Although stromal thickness was measured it was not possible to evaluate its relation to refractive error since the thickness of the stroma postoperatively is dependent on the amount of myopia that was corrected.

The results of this study show that central epithelial hyperplasia occurs postoperatively in eyes treated with small ( $5 \mathrm{~mm}$ or less) ablation zones. The retrospective refractive data on the study patients show that most of regression occurs in the early postoperative months as the hyperopic overcorrection subsides. Since it is clear that regression after PRK must be due to the treatment zone 'filling in' with tissue, it is not unreasonable to suggest that this tissue is at least in part the epithelium as others have shown histologically. The significant correlation found in this study between refractive regression and measured epithelial hyperplasia suggests that the two findings are related. A model of the relation between epithelial hyperplasia and regression was proposed stating that approximately $1.50 \mathrm{D}$ of regression was due to non-epithelial elements (a subepithelial lenticule and/or stromal remodelling) and that for each $18 \mu \mathrm{m}$ of epithelial hyperplasia an additional $1 \mathrm{D}$ of regression occurs. Prospective studies of topographical epithelial, subepithelial, and stromal thickness are needed to better delineate the contribution of the different corneal layers to regression.

The authors are grateful for financial support from the Australian Federal Government through the Cooperative Research Centres (CRC) Program, the Cooperative Research Centre for Eye Research and Technology, the Optometric Vision Research Foundation of Australia (Grant No SP94/35), the Swedish Medical Research Council (Project No 8655), the Karolinska Institutet, Kronprinsessan Margartas Arbetsnämnd, and StiInstitutet, Kronprinse

The authors acknowledge Sister Ann-Margrethe Eriksson

The authors acknowledge Sister Ann-Margrethe Eriksson,
Miss Alexandra Viding, Miss Helen Fischer, and Miss Inger Miss Alexandra Viding, Miss Helen Fischer, and Miss Inger
Nygårds for their assistance in conducting the study in Sweden, Nygards for their assistance in conducting the study in Sweden,
and Dr Helen Swarbrick for helpful comments on the manuscript.

1 Kahle G, Seiler T, Wollensak J. Report on psychosocial findings and satisfaction among patients 1 year after excimer laser photorefractive keratectomy. Refract Corneal Sur 1992;8:286-9.

2 Wilson SE, Klyce SD, McDonald MB, Liu JC,
Kaufman HE. Changes in corneal topography after excimer laser photorefractive keratectomy for myopia. Oph thalmology. 1991;98:1338-47.

3 Colliac JP, Shammas HJ, Bart DJ. Photorefractive keratectomy for the correction of myopia and astigmatism. $\mathrm{Am} \mathrm{F}$ Ophthalmol 1994;117:369-80.

4 Fantes FE, Hanna KD, Waring GO, PouliquenY, Thompson KP, Savoldelli M. Wound healing after excimer laser keratomileusis (photorefractive keratectomy) in monkeys. Arch Ophthalmol 1990;108:665-75.

5 Seiler T, Kahle G, Kriegerowski M. Excimer laser (193 nm) myopic keratomileusis in sighted and blind human eyes. Refract Corneal Surg 1990;6:165-73.

6 Binder PS. Excimer laser photoablation-clinical results and treatment of complications in 1992. [Editorial] Arch Ophthalmol 1992;110:1221-2.

7 Gartry DS, Kerr Muir MG, Marshall J. Excimer laser photorefractive keratectomy. Ophthalmology 1992;99:1209-19.

8 Dausch D, Klein R, Schröder E, Dausch B. Excimer laser photorefractive keratectomy with tapered transition zone for high myopia. $₹$ Cataract Refract Surg 1993;19:590-4.

9 Tuft S, Marshall J, Rothery S. Stromal remodelling following photorefractive keratectomy. Lasers in Ophthal mology 1987;1:177-83.

10 Marshall J, Trokel SL, Rothery S, Krueger RR. Long-term healing of the central cornea after photorefractive keratectomy using an excimer laser. Ophthalmology 1988;95: 1411-21

11 Steinert RF, Puliafito CA. Laser corneal surgery. Int Ophthalmol Clin 1988;28:150-4.

12 Fagerholm $\mathrm{P}$, Hamberg-Nyström $\mathrm{H}$, Tengroth B. Wound healing and myopic regression following photorefractive keratectomy - a histological and histochemical study. Acta Ophthalmol 1994;72:229-34

13 Beuerman RW, McDonald MB, Shofner RS, Munnerlyn CR, Clapham TN, Salmeron B, et al. Quantitative histological studies of primate corneas after excimer lase photorefractive keratectomy. Arch Ophthalmol 1994;112 1103-10.

14 Taylor DM, L'Esperance, Del Pero RA, Roberts AD, Gigstad JE, Klintworth G, et al. Human excimer lase Gigstad JE, Kintworth G, et al. Human excimer

15 Hanna KD, Pouliquen Y, Waring III GO, Savoldelli M, Cotter J, Morton K, et al. Corneal stromal wound healing in rabbits after 193-nm excimer laser surface ablation Arch Ophthamol 1989;107:895-901.

16 Goodman GL, Trokel SL, Stark WJ, Munnerlyn CR, Green WR. Corneal healing following laser refractive keratectomy. Arch Ophthalmol 1989;107:1799-803.

17 Gaster RN, Binder PS, Coalwell K, Berns M, McCord RC, Burstein NL. Corneal surface ablation by $193 \mathrm{~nm}$ excimer laser and wound healing in rabbits. Invest OphthalmolVis Sci 1989;30:90-8.

18 Courant D, Fritsch P, Azema A, Bernard F, Botineau J Legate $M$, et al. Corneal wound healing after photo-keratomileusis on the primate eye. Lasers and Light in Ophthalmology 1990;3:187-99.

19 Malley DS, Steinert RE, Puliafito CA, Dobi ET. Immunofluorescence study of corneal wound healing after excime laser anterior keratectomy in the monkey eye. Arch Ophthalmol 1990;108:1316-22.

20 McDonald MB, Frantz JM, Klyce SD, Beuerman RW, Vamell R, Munnerlyn CR, et al. Central photorefractive keratectomy for myopia. Arch Ophthalmol 1990;108: 799-808.

21 Hanna KD, Pouliquen YM, Waring III GO, Savoldelli $M$ Fantes F, Thompson KP. Corneal wound healing in monkeys after repeated excimer laser photorefractive keratectomy. Arch Ophthamol 1992;110: 1286-91.

22 Maloney RK, Friedman M, Harmon R, Hayward M, Hagen $\mathrm{K}$, Gailitis RP, et al. A prototype erodible mask delivery system for the excimer laser. Ophthalmology 1993;100:542-9.

23 Ramirez-Florez S, Maurice D. Inflammatory cells, refractive regression and haze after PRK. Invest Ophthalmol Vis Sci 1993;34(suppl):704.

24 Beuerman RW, McDonald MB, Shofner RS, Munnerlyn CR, Clapham TN, Salmeron B, et al. Quantitative histological studies of primate corneas after excimer laser photorefractive keratectomy. Arch Ophthalmol 1994;112: 1103-10.

25 Gauthier CA, Epstein D, Holden BA, Tengroth B Fagerholm P, Hamberg-Nyström $\mathrm{H}$, et al. Epithelia alterations following photorefractive keratectomy for myopia. F Refract Corneal Surg 1995;11:113-8.

26 Epstein D, Tengroth B, Fagerholm P, Hamberg-Nyström H. Excimer PRK for myopia. [Letter] Ophthalmology 1993;11: 1605-6.

27 O'Leary DJ, Wilson G, Henson DB. The effect of anoxia on the human corneal epithelium. Am $\mathcal{f}$ Optom Physiol Optics 1981;58:472-6.

28 Chan-Ling T, Pye DC. Pachometry: clinical and scientific applications. In: Ruben $\mathbf{M}$, Guillon $\mathbf{M}$, eds. Contact lens practice. 1st ed. London: Chapman and Hall Medical, 1994:414-20.

29 Holden BA, Polse KA, Fonn D, Mertz GW. Effects of cataract surgery on corneal function. Invest Ophthalmol Vis $\mathrm{Sci}$ 1982;22:343-50

30 Tuft SJ, Gartry S, Rawe IM, Merk KM. Photorefractive keratectomy: implications of corneal wound healing. $\mathrm{Br} \mathcal{F}$ Ophthalmol 1993;77:243-7.

31 Fitszimmons TD, Fagerhoim P, Härfstrand A, Schenholm $M$. Hyaluronic acid in the rabbit cornea after excimer lase superficial keratectomy. Invest Ophthalmol Vis $S c i$ 1992;33. $3011-6$. 